\title{
Editorial
}

\section{Continuing medical education}

The longest and most critically important phase of a doctor's medical education is the period after he or she has attained specialist/consultant status. Up until that point, the pressure to learn is motivated by the need to pass examinations and acquire particular skills. Thereafter, learning is generally unregulated and left to the interest, motivation, and perhaps the honesty of the individual. All of this is either about to change or, in some countries, has already changed. Doctors are now expected to conform with other professions, by showing society that they are both efficient and up to date in their knowledge and practice of medicine. The importance of such continuing medical education (CME) and professional development has been recognised for some time. ${ }^{1-5}$ Hitherto, participation has in general been voluntary. Increasingly, however, professional bodies in several countries are making such involvement obligatory (see box and figures $1-3$ ).

\section{Motivation for continuing medical education}

A variety of methods have been adopted, or are about to be used, to ensure that the individual doctor participates in his/her surveillance programmes (see box). These include financial penalties, such as those introduced in the UK in 1990 for family doctors (general practitioners). Currently, approximately $£ 2000$ of their annual income is conditional on their attending five days of approved educational activities each year. Over $90 \%$ of general practitioners fulfil these criteria and thereby receive their postgraduate educational allowance each year. Another approach, popular amongst the speciality societies in the US and Australia, is the use of time limits on the certification which a specialist receives having completed his/her training. Recertification or continuous certification is dependent on participation in CME. Penalties for failing to remain 'certified' might include the loss of certain rights to charge speciality fees. In

\begin{tabular}{|l|}
\hline Continuing medical education: acronyms \\
\hline MOCOMP $=\begin{array}{l}\text { Maintenance of Competence Programme } \\
\text { (Canada) }\end{array}$ \\
$\begin{aligned} \text { AMA PRA }= & \text { American Medical Association Physicians } \\
& \text { Recognition Award (USA) }\end{aligned}$ \\
SCOPME $=\begin{array}{r}\text { Standing Committee on Postgraduate Medical } \\
\text { and Dental Education (UK) }\end{array}$ \\
UNAFORIMEC $=$ L'Union Nationale des Associations de \\
Formation Medicale Continue (France)
\end{tabular}

\begin{tabular}{|lll|}
\hline $\begin{array}{l}\text { Continuing medical education: examples of } \\
\text { systems }\end{array}$ & Motivation & Requirements \\
\hline & Recertification & $100 \mathrm{~h} /$ year \\
UK hospital doctors & $\begin{array}{l}£ 2000 \text { of their } \\
\text { income }\end{array}$ & 5 days/year \\
UK general practitioners & Recertification & $50 \mathrm{~h} /$ year \\
USA & Recertification & daily diary \\
Canada & & \\
\hline
\end{tabular}

the future such continuing certification or accreditation may be considered mandatory by the doctor's employer.

\section{Approved activities for continuing medical education}

Doctors rely on many sources for continuing their medical education. Attendance at approved conferences or meetings has been the classical approach, perhaps because it is the easiest to monitor (see below). More recently, credit has also been given for presenting work, teaching, and getting papers published (box). Yet the technique most

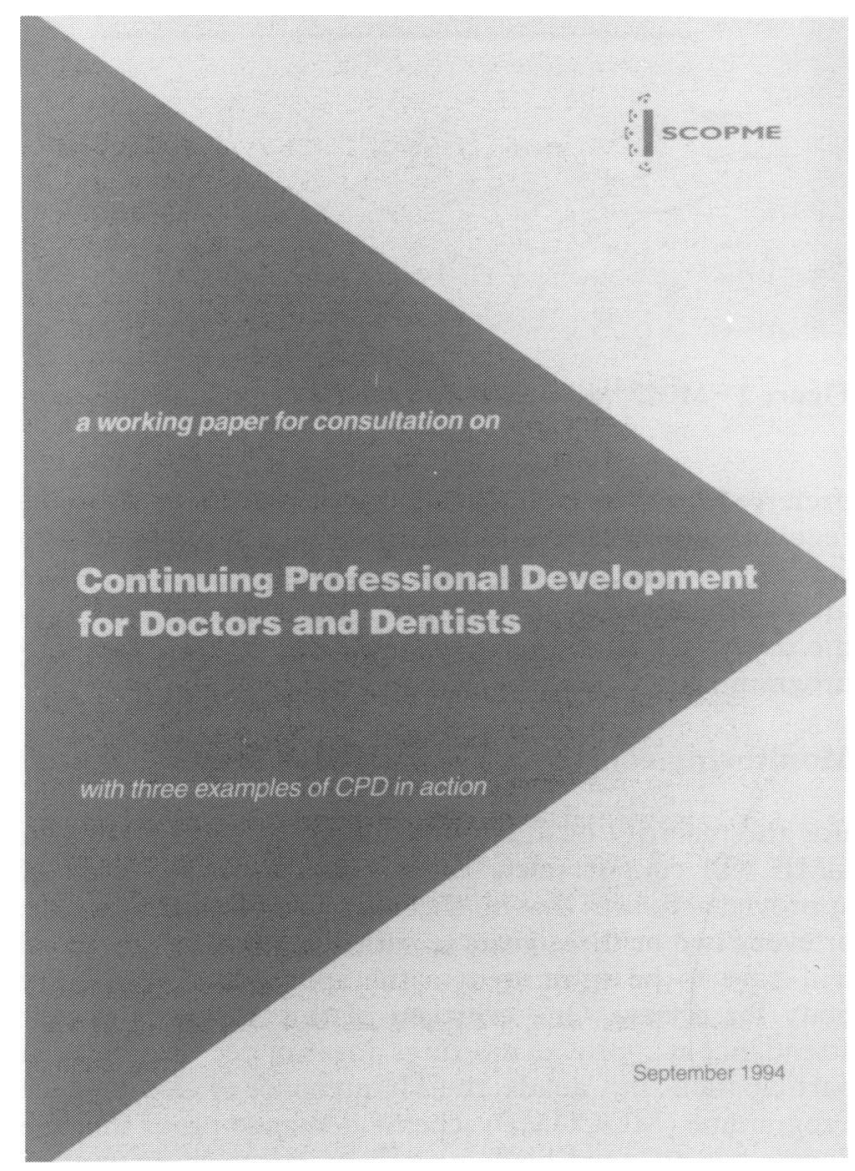

Figure 1 SCOPME working party report

\section{Continuing medical education: activities measured}

Attending approved meetings

Giving presentations Teaching

Getting papers published

Self-study methods (journal reading, use of audio-visual or computerbased material, etc) 


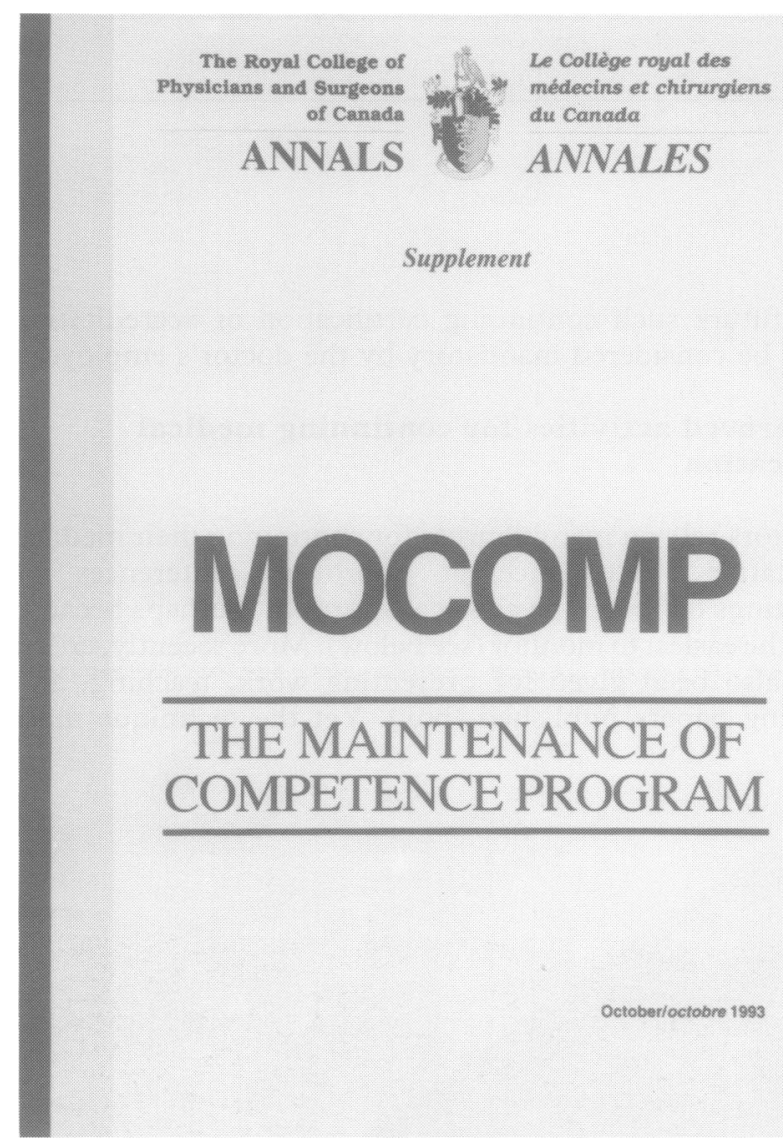

Figure 2 MOCOMP

preferred and used by doctors to keep up to date, namely by regular reading of general and specialist journals, is only considered credit-worthy in Canada and the US. More imaginative approaches are also being considered, such as the use of self-assessment schemes and distance learning programmes.

\section{Monitoring continuing medical education}

For the majority of doctors, evidence of participation in CME will consist solely of collating a list/log book of approved activities that he/she has undertaken. Each year, or every two or three years in some countries, that record will have to be submitted to the appropriate regulatory body for review. One criticism of this approach is that attendance at approved meetings does not necessarily mean participation. In Canada, the Maintenance of Competence Programme (MOCOMP) scheme demands proof that the doctor has changed his/her work practices as a result of participation in educational activities. This imaginative monitoring system makes use of a computerised diary to record the outcome of $\mathrm{CME}$ activities. These data are then transferred electronically to the MOCOMP office. Random audits of annual MOCOMP profiles will be undertaken by peers to review the impact of CME activities on that individual's practice.

\section{Paying for continuing medical education}

Many professionals outside medicine (eg, lawyers in the UK) have to pay out of their own pocket for their continuing professional development. For the majority of doctors this is not the case. Attendances at conferences and subscriptions to medical journals in some countries are tax-deductible. Doctors attending CME courses in France

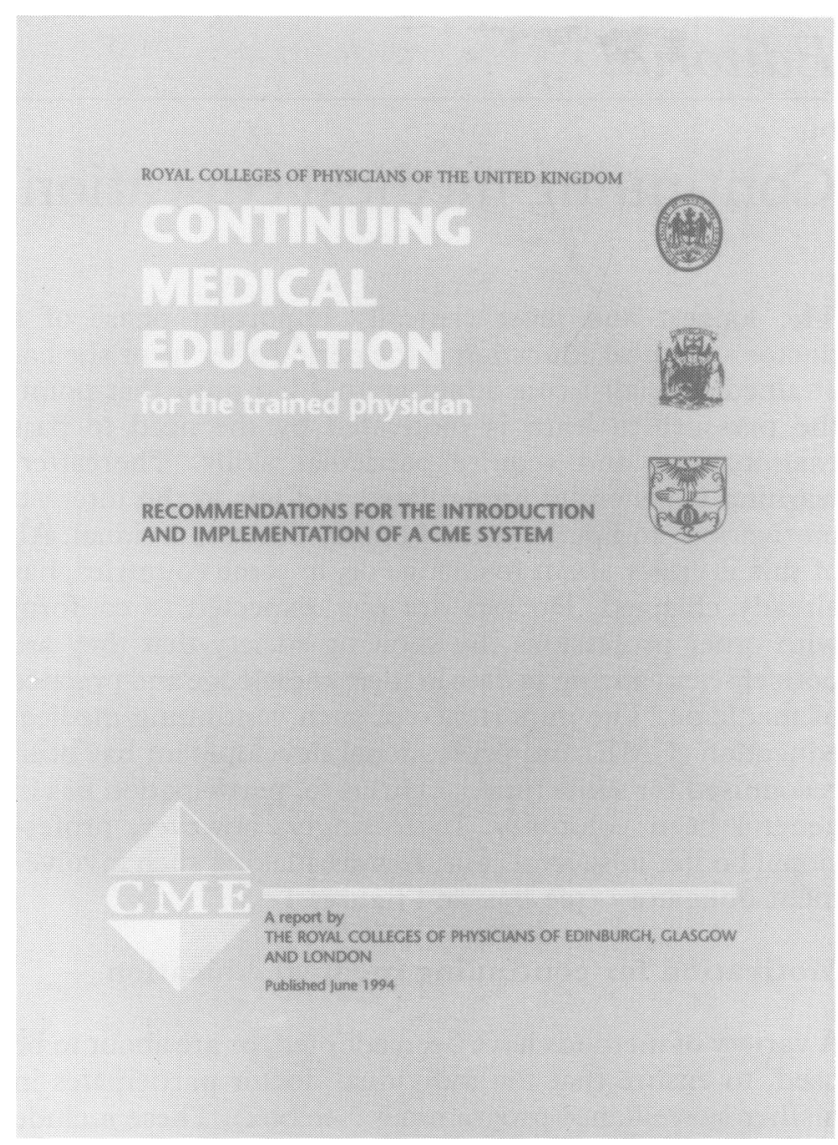

Figure 3 Royal College of Physicians CME Report

receive payment for the loss of fees thus incurred. Hospital doctors in the UK are allowed 10 days study leave (with expenses) per annum to attend approved conferences, though such paid leave is not routinely allowed for selfdirected study such as reading, literature searches, teaching and research.

\section{Strategies for CME}

Historically, CME has concentrated predominantly on updating knowledge in line with the concept of a continuum of medical education from medical school to retirement. Newer strategies in CME will focus on models for individual educational support (box). Their aims are to encourage doctors to take more responsibility for their continuing education and to increase their ability to inquire and make critical judgements.

\section{Conclusions}

The pressures placed on practising clinicians are increasing at a phenomenal pace. As a consequence, clinicians have to

\section{Continuing medical education: models for individual educational support}

Mentor: a person with established expertise as a catalyst for self-learning

Buddy model: two equal professionals evaluate their development non-judgmentally

Co-tutors: two equal professionals actively coach and learn from each other

Portfolio-based learning: using documented experiences as a framework for self-appraisal 
prioritise their time. For the majority it is the time spent on CME that is being eroded. Clinicians may feel that the importance society is now attaching to CME is yet another burden in what is already a very busy life. Hopefully clinicians will not simply ignore these advances, but use them to their own advantage. Successful CME requires both an environment of encouragement and adequate resources. Its implementation will be to the benefit of society in general, and to its medical specialists in particular.

CHARLES RK HIND Editor
1 Hind CRK. Coping with change. Postgrad Med f 1995; 71: 1-3

Continuing medical education for the trained physician. Glasgow and London: Royal Colleges of Physicians of Edinburgh, 1994; 1-14.

3 Continuing professional development for doctors and dentists. London: SCOPME, 1994; 1-40.

4 MOCOMP. Ann R Coll Physicians Surg Canada 1993; 26: 51-64

525 Years in continuing medical education. $\mathcal{F} A M A$ 1993; 270: 1092
Paul Turner, who died on Christmas Day 1994, was an academic and clinical pharmacologist of international renown. He had been Hon Secretary to the Fellowship of Postgraduate Medicine from 1980 to 1984 and President from 1986 to 1993.

He trained in medicine at the Middlesex Hospital and following medical appointments at the Royal Free and Edgware General Hospital he was appointed lecturer in pharmacology and clinical pharmacology at St Bartholomew's Hospital in 1963.

It was this department that he led subsequently as Professor of Clinical Pharmacology and consultant physician from 1972 until his retirement in 1993. During this time his involvement in, and contribution to, clinical pharmacology and medical education was outstanding by any measure. Both as teacher and researcher as well as with his interest in the application of clinical pharmacology to patient care, Paul's reputation was international, especially in Australia, India, Africa and China.

Paul had a major influence on the world of medical journals, being founder editor of the British fournal of Clinical Pharmacology and of Human Toxicology. For many years he was a member of the editorial board of the Postgraduate Medical fournal making major contributions to the journal itself and to the management of it and its supplements.

For some 15 years he chaired the Committee on Toxicity of Chemicals in Food, Consumer Products and the Environment for the Department of Health and was for 14 years the vice chairman of the British Pharmacopoeia Commission where his ideas and sound practical common sense shaped many of the changes which occurred in British clinical pharmacology during this time. He was made a Commander of the British Empire (CBE) in the New Year's Honours in 1992.

In addition to his remarkable energy and infectious enthusiasm he always found time to help those who sought his support. His contribution to the Fellowship, to which he devoted himself wholeheartedly, did not flag despite recent illness.

Following his retirement from St Bartholomew's his committment seemed rather to increase and as vice

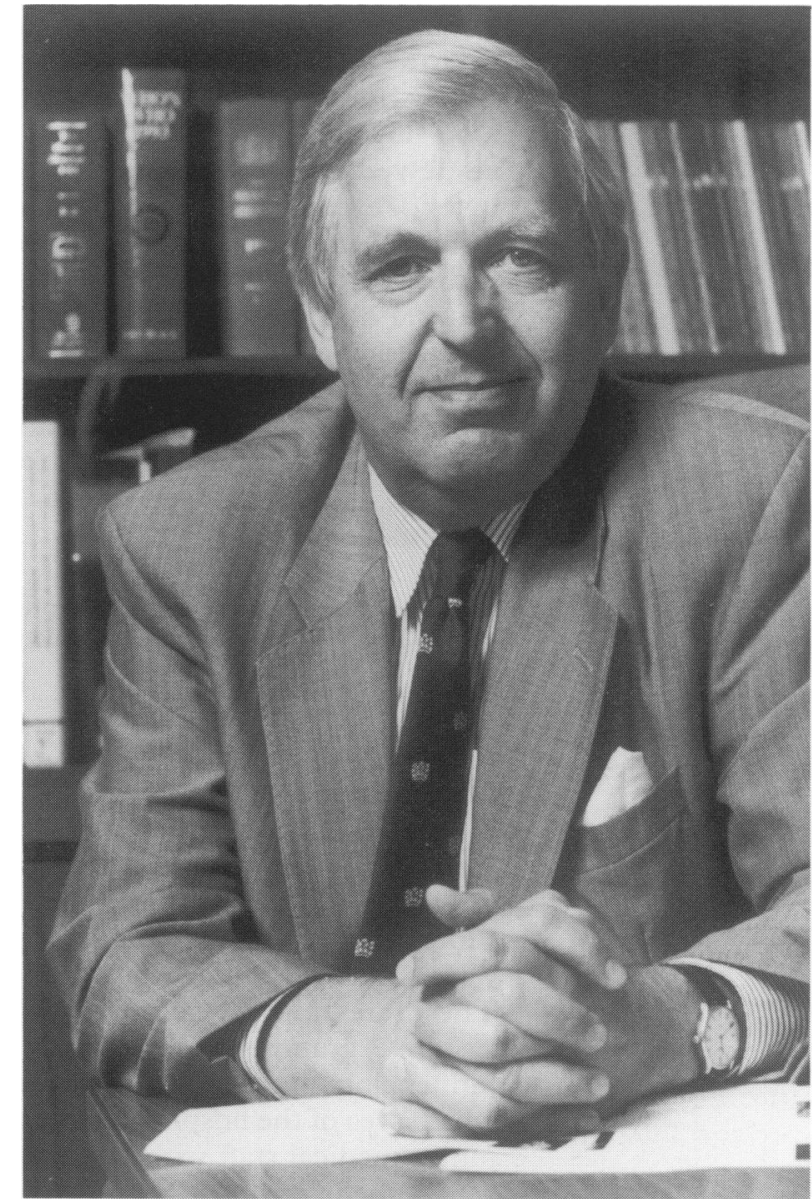

president of the Fellowship he continued to give wise advice and practical help to Council in addition to his many other demanding academic posts in London.

Those who have worked with him over the years will miss those qualities of intellect, energy and good humour, and above all, leadership, which Paul brought to everything he did; none will miss these more than the Fellowship. 